تتتاول هذه الدراســة تقديم صــورة تحليلية لطالب التعليم الفني نظام الثلاث ســنوات: صـــناعي، تجاري وفندقى، زراعي. والدراســــة تهتم بالدرجة بالجوانب الاجتماعية والإنسانية لطالب التعليم الفني، الذي يمثل نقطة انطلاق العمالة الفنية. طالب التعليم الفني شـاب في مقتبل العمر ينتمي للمرحلة العمرية (10 1 1 ) ســنة،

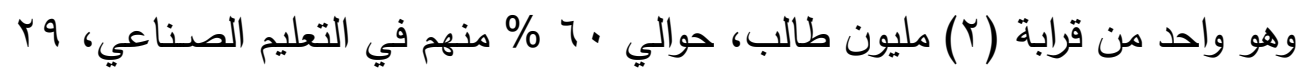
\% في التعليم التجاري، 11 1 \% في التعليم الزراعي. نســـبة البنين إلى البنات بينهم تتراوح حول §o \% إلى 7؛ \% مع زيادة نســبة البنات عن نســبة البنين في التعليم

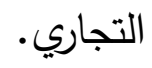

\title{
مشكـلة البحـث:
}

يأتي طالب التعليم الفني - في غالب الأحوال - عن غير رغبة حقيقية في الالتحاق بمنظومة التعليم الفني ولكنه يلحق به نتيجة تنسـيق لخريجي المرحلة الإعدادية يكون

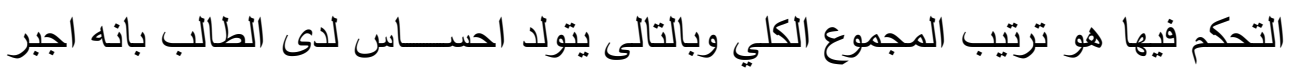
على الالتحاق مدارس التعليم الفنى مما يؤدى تغلب الظن الى حدوث حاجز نفســى بينه وبين هذا المجتمع الجديد الذى اجبر عليه نعكس بثـكل واضـح على سـلوكياته داخل وخارج المجتمع المدرسى.

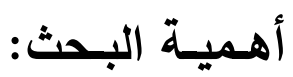

1- التعرف على أسلوب القبول في نظام التعليم الثانوي الفني "التعليم قبل الجامعى". r- التعرف على الثريحة الاجتماعية التى ينتمى اليها طالب التعليم الثانوي الفني. r- دراسة الحالة النفسية لطالب التعليم الثانوي الفني. ع - دراسة سلوكيات طالب التعليم الثانوي الفني "التطرف والخلل القيمي". 0- القاء الضوء على مستقبل طالب التعليم الفني وانعكاس ذلك على القيم الاخلاقية. 


\section{واقع ازمة القيم فى التعليم الفنى قبل الجامعى الطلاب" ــــ/ محمد احمد محمد عبد المقصود}

\section{أهـداف البحث:}

1- إعداد اختبارات ومقاييس قدرات وميول وتوظيفها - بطرق إرشادية - فى قبول الطلاب. r- تحديد اليات لتطوير الخطط الدراسية البرامج التدريبية بما يلائم الواقع العملى.

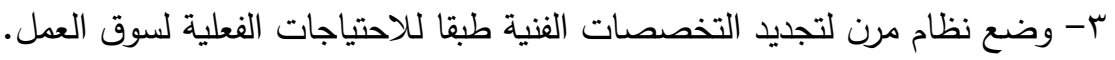
ع- مراعاة ان تتضمن المناهج مايدعم القيم الأخلاقية بصفة عامة والسلوكيات السوية لاحئ خاصة. 0- استحداث برامج ثقافية تعمل على تتمية المرونة العقلية للطالب وتتمية مهارات التنكير .

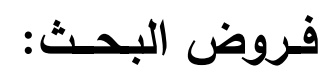

$$
\text { ( ).... دراسة الاتى: }
$$

1- الشريحة الاجتماعية لطالب التعليم الثانوي الفني. r- الحالة النفسية لطالب التعليم الفني. r- سلوكيات طالب التعليم الفني. ع - مستقبل طالب التعليم الفني.

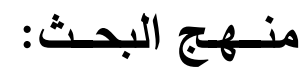

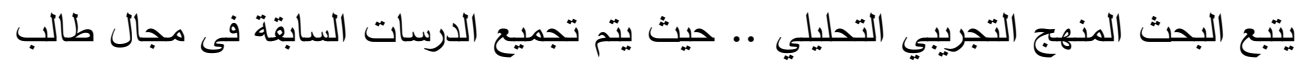
التعليم الفنى "ما له وما عليه"، منها دراسات وبحوث على طلاب وخريجي التعليم الفنى للتعرف على توجهاتهم وتطلعاتهم والصعوبات العلمية والنفسية التى قد يعانونها، وأرائهم فى تطوير التعليم الفني من واقع خبراتهم.

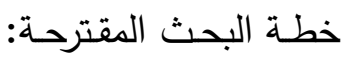
يتضمن البحث ثلاثة أبواب كالآتي: - البـاب الأول: تعريف طالب التعليم الفني. - الباب الثاني: كيفية تعليم طالب التعليم الفنى. - الباب الثالث: جهود وزارة التعليم الفني.

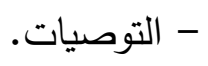

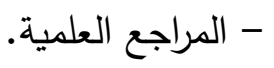




\section{البـاب الأول}

\section{تعريف طالب التعليم الفني}

\section{تعريف طالب التعليم الفني:}

بعيداً عن التعميم الكاسح يكون طالب التعليم الفني من أصحاب المجاميع المنخفضة بالنسبة

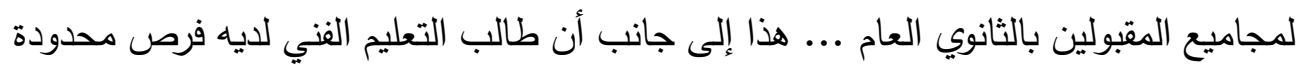
في اختيار مجال التخصص الفني حتى داخل منظومة التعليم الفني التي قَبل بها ل... ولابد من الإثارة هنا إلى أنه توجد أعداد قليلة من الذين يلتحقون بالتعليم الفني من الحاصلين على الحى

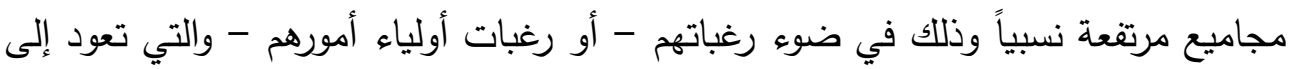
الرغبة في الانتهاء من التمدرس والتعليم في أقصر مدة ممكنة (بعد التعليم الأساسي الإلزامي)

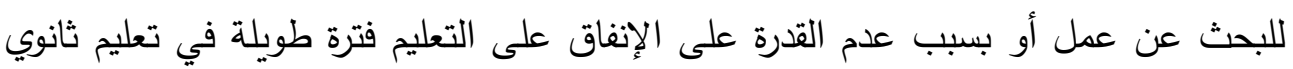
عام يليه تعليم عالي / جامعي. الشريحة الاجتماعية لطالب التعليم الثانوي الفني: طالب التعليم الثانوي الفني ينتمي في غالب الأحوال إلى شريحة اجتماعية تتراوح بين الثريحة العليا من الطبقة الفقيرة وبين الثريحة الدنيا من الطبقة المتوسطة، الكثيرون من وجهاء الطبقة الوسطى والطبقة العليا، ومن المسئولين في التعليم وغير التعليم، يمتدحون ويتمنون التعليم

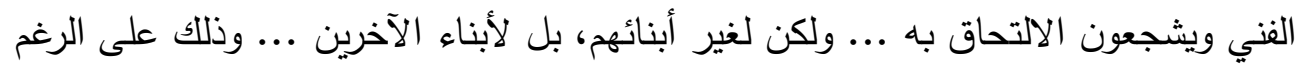
من أنه في بعض الحالات - خاصة بعد ظاهرة ارتفاع المجاميع في الثانوية العامة - تبين أن فرص التحاق خريجي التعليم الفني - نظام الخمس سنوات - كانت أفضل من خريجي الثانوية العام في الالتحاق بالتعليم الجامعي، كما وأن بعض خريجي التعليم الفني شقوا طريقهر بنجاح سواء في قطاع الأعمال أو قطاع الوظائف الحكومية الرفيعة.

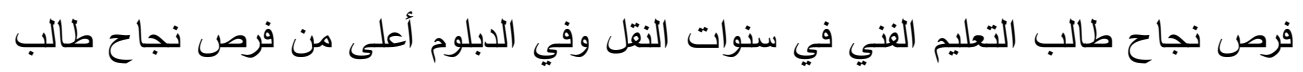

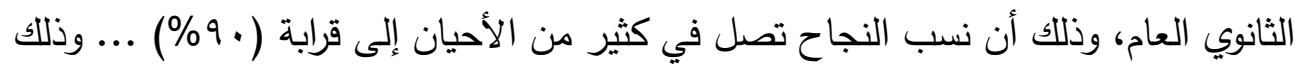
على الرغم من أن طالب التعليم الفني لائد من تعاطي الدروس الخصوصية، كما هو الحال عند غالبيته - إن لم يكن كل - طلاب الثانوي العام. 
واقع ازمة القيم فى التعليم الفنى قبل الجامعى الطلاب" د. م/ محمد احمد محمد عبد المقصود

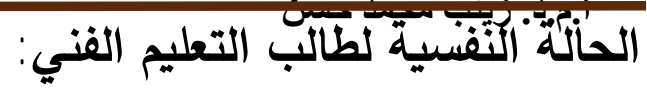

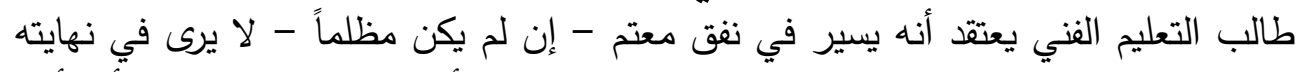

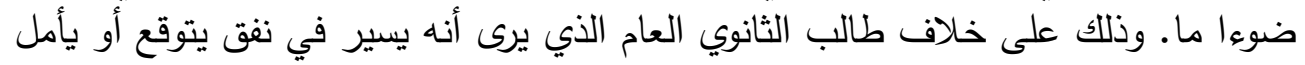

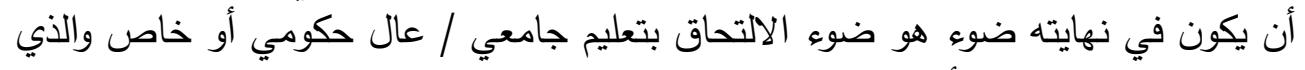

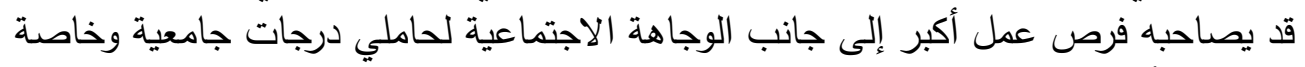

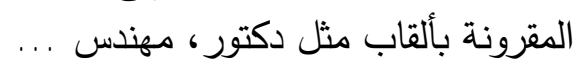
وعلى الرغم من ذلك فإنه إذا سارت السياسة التعليمية على درب درب أن الثاب الثانوية العامة مرحلة

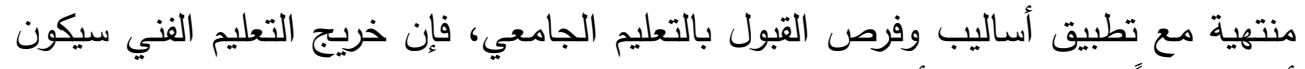

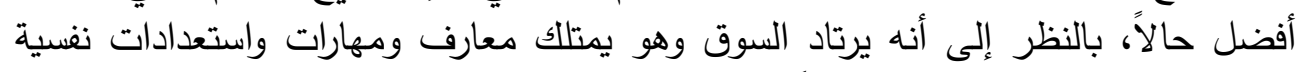

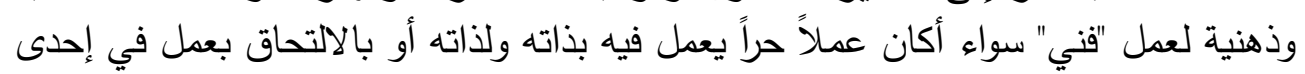

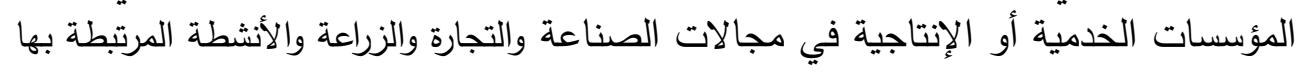
في سوق العمل والتي في حاجة إلى عمالة فنية.

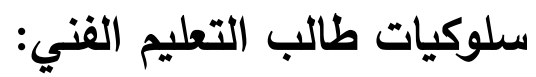
يعيش ويعايش طالب التعليم الفني بيئة تعلم تعاني الحياة الطلابية فيها من مشكلات "شبابية"

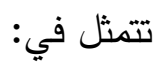

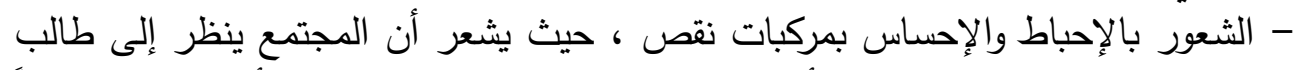

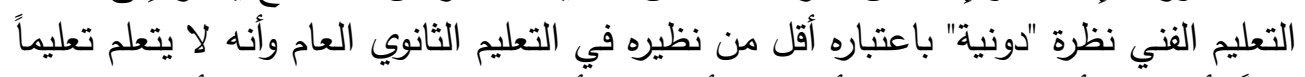

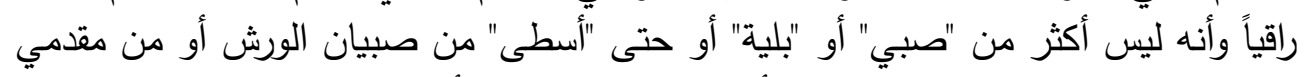

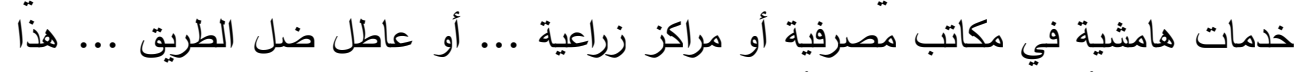

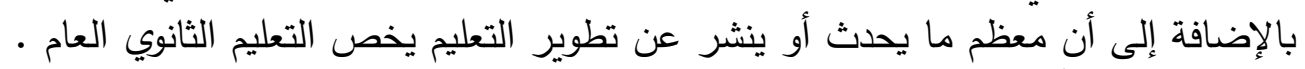

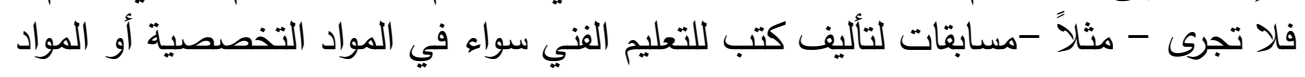

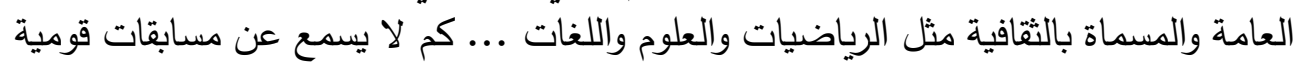

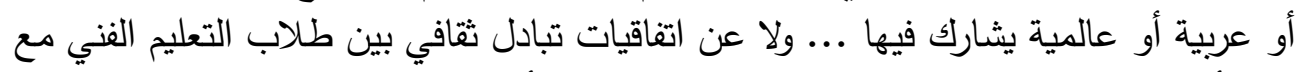

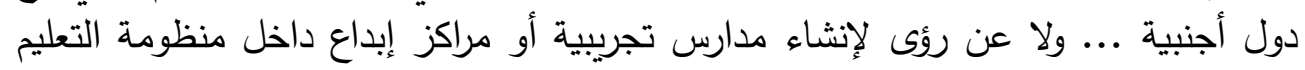

\section{مستقبل طالب التعليم الفني:}

هذا بالإضافة إلى التخوف من شبح البطالة والبقاء حبيس المنزل أو التسكع في الثوارع

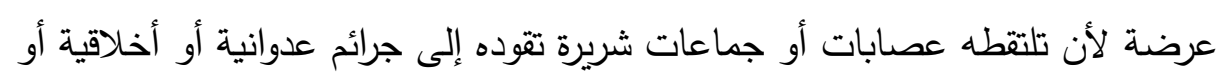




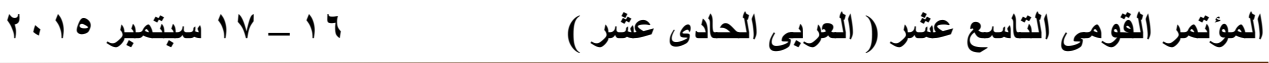
انحرافات سلوكية ... يصاحب ذلك ظاهرة الهروب من الددرسة والتواجد المتكرر في الشوارع وعلى المقاهي وأحداث التحرش بفتيات وفتيان. - التذخين والتدخين على طريق الإدمان ... يحدث ذلك سراً أو علانية والذي قد يصاحبه تعاطياً لمواد مخدرة ... بل أن بعض الطلاب يشاركون خفية في توزيع مواد مخدرة تحت ضغط الفقرئ

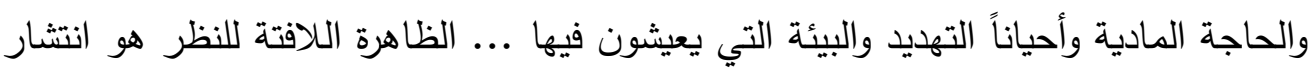
تدخين السيجارة والشيشة عن بعض الفتيات، وان كان ذللك ليس قاصراً على فتيات التعليم الفني.

\section{- التطرف والخلل القيمي: -}

هذه ظاهرة عامة في الشارع التعليمي بمراحله المتوسطة والجامعية ... ولكنها تزداد عند من يعانون الإحباط ... يعود ذللك إلى مناهج خفية بعضها تسلل في كتب مدرسية وبعضها يقال

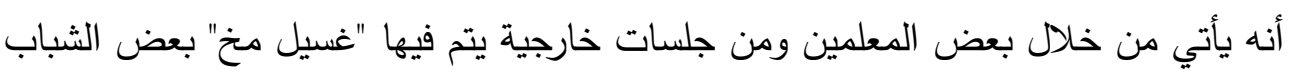

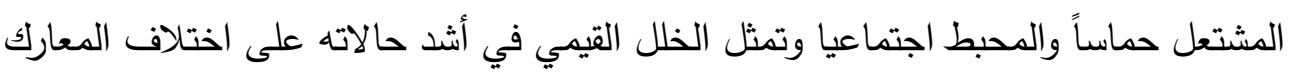
وممارسة العنف والاعتداءات غير المبررة والحض على الكراهية وعدم تقبل الآخر ورفض اهض الالتزام بالشرعية والقانون والابتعاد عن صحيح الدين ... ظاهرة العنف وحل المنازعات بطرق لهرية عدوانية لم تقف عند حد الطلاب وبعضهم البعض بل طالت منازعات عنيفة بين طلاب ومعلمين وإدارين وأولياء أمور ... وقد وصل الأمر في بعض الأحيان إلى دخول أسلحة بيضاء إلى بعض المدارس ... مما أفقد غالبية الطلاب الإحساس بالأمن والأمان والثعور بأنهم في مؤسسة تربوية. 
واقع ازمة القيم فى التعليم القنى قبل الجامعى الطلاب" د. م/ محمد احمد محمد عبد المقصود البـاب الثانى

كيفية تعليم طالب التعليم الفنى

كيفية تعليم طالب التعليم الفنى:

طالب التعليم الفني يجري تعليمه من خلال مناهج لا تتواكب في بعضها مع المتطلبات العالمية للعمالة الفنية المعاصرة حيث بعضها مختلف وبعضها آيل للسقوط في ضوء التقدم الحادث معرفياً وتكنولوجياً بأهمية التعليم الفني القائم على تعدد المهارات والمرونة العقلية، جدير بالإشارة هنا إلى تدني الاهتمام بالتدريب العملي ... على سبيل المثال

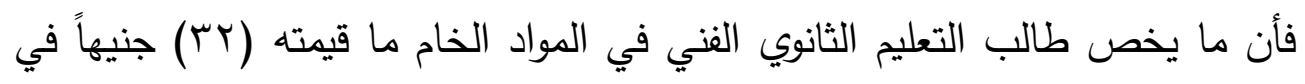
التعليم الصناعي، (7 ( ) جنيهاً في كل من التعليم التجاري الزراعي زادت مؤخرا لتصل الى (•0) ولكنها مازالت غير كافية في العام الدراسي.

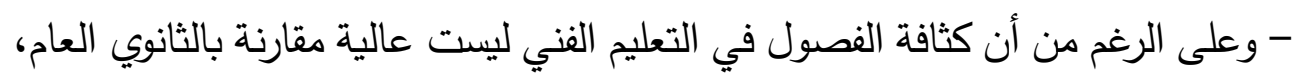

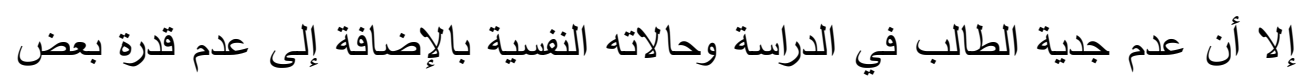
المعلمين على ضبط النظام داخل الحصة أو الفترة الدراسية من أسباب ضعف الته التحصيل الأصيل معرفياً ومهارياً ... وذلك على الرغم من ارتفاع نسب النجاح في الامتحانات والاختبارات ومن ناحية أخرى فإنه من الصعب التعميم المطلق بأن ضعف المناهج هو السبب الوحيد في ارتفاع نسبة البطالة بين خريجي التعليم الفني ... ذلك أن السبب الأكبر والأعظم هو ضالة أو ضيق مساحة الفرص المتاحة للعمل، وتسارع الزيادة السكانية وعشوائية الأعمال التي يقوم بها بعض الخربجين بعيداً عن إعدادهم المهني (اكسابهم المهارة المهنية المناسب لاحتياجات سوق العمل) والهروب إلى أعمال هامشية مثل العمل بالمقاهي ومنادي السيارات وحارسي منازل وأفراد أمن بل - عمل البعض - خاصته الفتيات - بالخدمة في المنازل - والعمالة باليوم في المواسم الزراعية ...

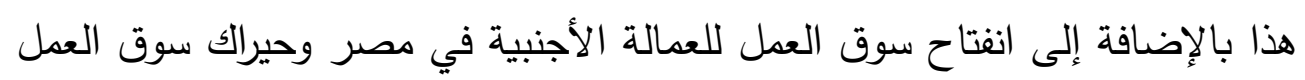


في الداخل والخارج في ضوء عولمة جامحة وتتافسية والحاجة إلى عمال متعددة المهارات كثيفة المعرفة.

- يتلقى ويتدرب طالب التعليم الفني على أيدي معلمين يأتون من الكلية على المدرسة

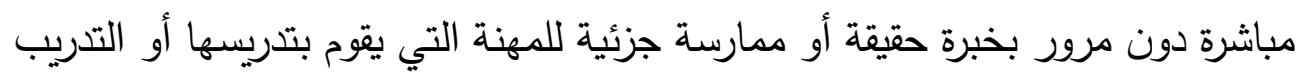
عليها ومن ثم فان طرق التدريس في معظمها مجردة وجافة ووصفية ... وبعيدة عن من مبرة واقع العمل المهني الفعلي كما وأن معلمي المواد المسماة بالثقافية زاهدون في العمل بمدارس التعليم الفني لضعف الحوافز ولديه إعطاء دروس خصوصية، مع الإحساس بصعوبة التعامل مع الطلاب وأولياء أمورهم ... وقلة اهتمام الوزارة بهم مقارنة بأقرانهم في التعليم الثانوي العام.

\section{العوامل المؤثرة فى تعليم طالب التعليم الفنى:}

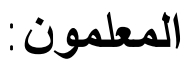

.... - هنالك ثلاثة أنواع من المدرسين

أولا: مدرسو مواد الثقافة العامة (مثل اللغات والرياضيات وغيرها) وعادة ينقل لمدارس الوس التعليم الفني لتدريس هذه المواد المدرسين الأقل كفاءة أو مثيري المشاكل أو حديثي التخرج ممن يعملون بعقود مؤقتة ما يؤدى إلى ضعف المستوى الثقافي لطلاب التعليم

الفني.

ثانيا: مدرسو المواد الدراسية العلمية الفنية وهم إما من خريجي كليات الهندسة أو كليات التربية أو كليات التعليم الصناعي ويتميز خريجو كليات الهندسة وهم الأقل عددا بالكفاءة العلمية بينما يتميز خريجو كليات التربية بمهارات التدريس اما خريجو كليات التعليم الصناعي فهم من يقوموا بتدريس المواد النظرية والتدريبات العملية وعادة يكونوا غير مؤهلين ذلك، أما المشكلة الكبرى في بعض المحافظات وخاصة محافظات الوجه القبلي 


\section{واقع ازمة القيم فى التعليم الفنى قبل الجامعى الطلاب" ـــ م/ محمد احمد محمد عبد المقصود}

فتتمثل في قيام مدرسو التدريبات العملية بتدريس المواد العلمية الفنية لسد العجز في إعداد مدرسي المواد العلمية الفنية مما يؤثر سلبا على المستوى الطلاب بشكل عام. كذلك فإن فكرة التعاقد المؤقت مع حديثي التخرج لتدري المواد العلمية دون وجود ضوابط موضوعية تحكم هذه التعاقدات قد ساهم فى تدنى المستوى العلمي لطلاب التعليم الفني ثالثا: مدرسو التدريبات العملية وعادة مايكونوا خريجي الدبلومات الفنية نظامي الثلاث أو الخمس سنوات أو الدراسات التكميلية (دراسة لمدة سنتان بعد الحصول على دبلوم الدراسة الفنية نظام الثلاث سنوات) وفى بعد التخصصات يكونوا خريجي كليات التعليم الصناعي. وتلك النوعية من المدرسين والتي لم تحصل على اى تأهيل للتدريس قد ساهمت هي الأخرى في تدنى مستوى العملية التعليمية وخاصة فى مجال التعليم الصناعى. والرغم من أن المعلم هو الركن الاساسى فى العملية التعليمية فان معلم التعليم الفني يعانى بشكل كبير من تداعيات انخفاض مستواه الاقتصادي والاجتماعي وتقليص صلاحياته في تقويم الطلاب مما تسبب في انحسار دوره بشكل كبير ، ولقد أدى تدنى مرتبات المعلمين وخاصة بالتعليم الفني إلى انشغال معظمهم بأعمال أخرى قد لاتكون مهنية او تكسبهم خبرة في مجال تخصصاتهم. تخصصات التعليم الفني: تتسم التخصصات الموجودة فى التعليم الفنى حاليا بالتقليدية وعدم مواكبتها للتطور التكنولوجي والمهني، مما تسبب في زيادة نسبة البطالة بين خريجي التعليم الفني في الوقت الذي تقل فيه نسبتها بين غير المتعمين حيث يزيد الطلب عليهم في المجالات التي لا تتطلب مهارات ذات مستوى مهارى مرتفع مثل إعمال البناء وتجارة التجزئة 
والحرف التقليدية، ولكن هذا الاتجاه يتغير بسرعة حيث بدأت الصناعة المصرية فى مواكبة التغيرات التكنولوجية مما يتطلب تخصصات جديدة واستخدام مهارات حديثة.

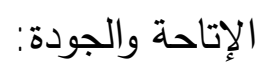

تسببت سياسة الإتاحة المفتوحة لاستيعاب طلاب ليس لهم مكان فئ نظم التعليم الأخرى فى تكديس الطلاب بالتعليم الفني دون آن يقابل ذلك استعداد حقيقي لاستقبال إعداد

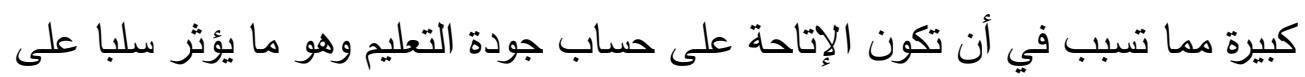
سوق العمل وخطط التتمية إضافة إلى زيادة معدل البطالة. المنهج الدراسي والكتاب المدرسي: تتصف المناهج وأساليب التدريس والتدريب فى التعليم الفنى بالجمود فى معظمها بل أحيانا بالتخلف عن مسايرة الاتجاهات الحديثة، حيث لا تتيح للطلاب فرصة للابتكار والإبداع او تبنى بداخلهم القدرة على المبادرة الفردية واحترامها والتتافس الثريف والعمل به فى فريق، اضافة الى تحفيز الرغبة المستمرة فى التعلم الذاتى وتتمية المهارات طبقا

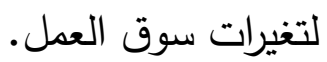
وعلى الرغم من ان عملية التطوير للمناهج الدراسية تتم باستمرار إلا إن فكرة تطوير المناهج غير واضحة في أذهان المتخصصين القائمين على هذا التطوير فنجد في كثير من الأحيان ان عملية التطوير تنحصر في تعديل أو إضافة أو حذف أو نقل أبواب من منهج لأخر دون وضوح الهدف من هذه العملية.

\section{الورش والمعامل والوسائل التعليمية:}

يتناقض واقع تجهيزات المدارس الفنية مع الفرص المتاحة فبعض المدارس تعانى من نقص حقيقي في المعدات وتجهيزات المعامل سواء كما أو كيفا وهناك مدارس أخرى تتوافر بها احدث التجهيزات ولكنها لاتستخدم بكفاءة لأسباب تتراوح مابين الخشية من 


\section{واقع ازمة القيم فى التعليم الفنى قبل الجامعى الطلاب" ـــ م/ محمد احمد محمد عبد المقصود}

استخدامها مما قد يتسبب فى تعطيلها ومجازاة المسئول أو عدم توافر قطع الغيار أو الخامات اللازمة للتشغيل او عدم توفر ميزانيات للصيانة.

\section{الإدارة والتنظيم:}

يعاني التعليم الفني بمستوياته المختلفة من البيروقراطية والمركزية المفرطة والتي لا تسمح بمواجهة الاحتياجات المحلية أو بإنشاء برامج لتأهيل ورفع مستوى الكوادر المحلية.

\section{المرونة في نظام التعليم:}

لا توجد مسارات أفقية أو رأسية للاتصال بين نظامي التعليم والتدريب تسمح بالدخول

فيه والخروج منه وتبادل مساراته وفقاً للقدرات المطلوبة وإمكاناتهم وظروفهم الحياتية.

الأنشطة الطلابية:

تتعدم الأنشطة الطلابية تقريبا في المدارس الفنية لعدم وجود مساحات كافية للأنشطة العامة و الرياضية وهو ما يؤثر سلبا علي تحصيل الطالب وتتمية قدراته ـ إضافة إلي اعتقاد العديد من المسئولين بكلا المدارس بعدم جدوى مثل هذه الأنشطة و بالتالي فهم لا يقومون بها أو حتى لا يشجعونها. المواصفات القياسية لخريجي التعليم الفني: لا تتوافر أو تطبق مواصفات محددة وملزمة لخريج التعليم الفني بمستوياته وتخصصاته المختلفة. 
البـاب الثالث

\section{جهود وزارة التعليم الفني}

\section{جهود وزارة التعليم الفني:}

اولا: فيما يخص تطوير المناهج والكتب الدراسية والعملية التعليمية: 1- تطوير المناهج لتلبي احتياجات سوق العمل "ضرورة تعليم الطلاب مهارات التفكير مع المهارات الأساسية "التكامل بين التعليم الفني والتدريب ليحقق التطوير مبتغاه في

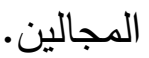

r - تضمين محتويات الكتب للجوانب المعرفية والمهارية والقيمية، بالإضافة الى توظيف مقرر الأمن والسلامة المهنية بما يناسب كل تخصص. r- توظيف التخصصات المختلفة بمدارس التعليم الفني وما تتضمنه من محتويات لخدمة البيئات والمجتمعات المصرية المختلفة. ع- تطوير شامل للمناهج الخاصة بالتعليم الفني حيث سيتم إضافة مفاهيم خاصة بالأخلاق والقيم، وكذلك متطلبات الأمن والسلامة. 0- تطبيق الاطار القومى للمؤهلات المهنية فى المناهج الدراسية المطورة بنوعيات التعليم الفنى (صناعى - زراعى - تجارى - فندقى).

ثانيا: فيما يخص انضباط واحترام العملية التعليمية واكساب المهارات: ا - إدخال مفاهيم الانضباط والاحترام في المدارس الفنية "بـ مدرسة تعليم فنى" سوف

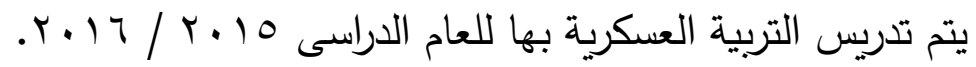
Y- إصدار القرار الوزارى رقم \& ا لسنة 0 ـ ـ " "ينص على تشكيل لجنة لمتابعة التعليم

والتدريب المزدوج / محافظة وذلك بمعاينة المصانع وجدية تتفيذ الخطة التدربية". r- توقيع بروتوكول مع مؤسسة مصر الخير لتنفيذ مشروع تتمية مهارات اللغة العربية لطلاب التعليم الفني. 
و اقع ازمة القيم فى التعليم القنى قبل الجامعى الطلاب" د. م/ محمد احمد محمد عبد المقصود ثالثا: التاهيل الادارى والفنى لمديرى المدارس والتنمية المهنية لمعلى التعليم الفنى: ا - برنامج اعداد القيادة المدرسية على تحسين جودة العملية "التميز التعليمى - الادارة العملية - القيادة الاستراتيجية" بالتعاون مع المركز الثقافى البريطانى. r- وضع معايير معلمى التعليم الفني بنوعياته الاربعة (صناعى - زراعى - تجارى - فندقى) طبقا للتسلسل الوظيفى. r- تنفيذ خطة التدريب "تتمية مهارات مدرسى التدريبات المهنية" فى جميع تخصصات التعليم الفنى .. البدء بتخصص الملابس الجاهزة بمديرية التربية والتعليم بالقاهرة.

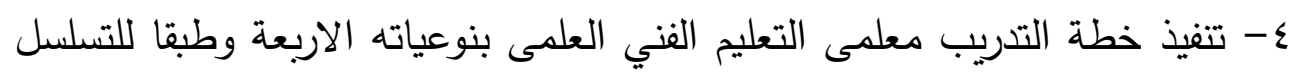
الوظيفى بالتعاون مع الاكاديمية المهنية للمعلمين.

\section{رابعا تعديل مسارات ونوعيات التعليم الفنى وتخصصاته طبقا الاحتباجات}

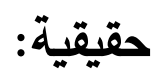

ا - تفعيل الهدف استراتيجي لوزارة التعليم الفنى والتدريب وهو "التعليم فى بيئة العمل" بالتوسع من خلال عدة بروتوكلات تعاون بانشاء مدرسة داخل المصنع. r- التوسع فى التعليم المزدوج، حاليا يوجد ب ب مدرسة داخل المصنع، بالإضافة الى لى

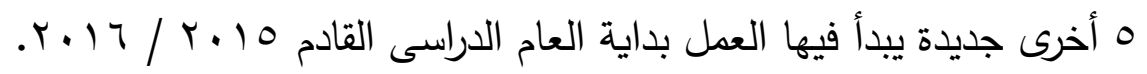
r- إصدار القرار الوزارى رقم ... لسنة 10 . ب بالتوسع فى نظام المدارس الثانوية

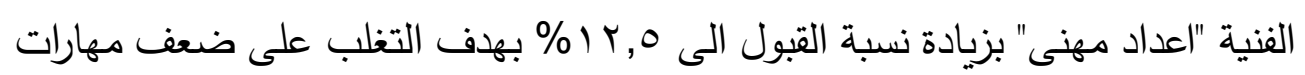
الخريجين. ع- انثاء مدرسة ثانوية فنية للتعليم والتدريب المزدوج داخل مصنع بالتعاون المجموعة البافارية للسيارات بي ام دابليو فى مهنة فني صيانة وإصلاح السيارات. 
1 - تشكيل وحدة تيسير الانتقال إلى سوق العمل، والتى تم من خلالها تشغيل حوالى r ألف خريج حتى الان. r- التعاون مع منظمة التتمية الصناعية UNIDO بشان تنمية المهارات طلاب التعليم الفني وفقا لاحتياجات سوق العمل "تدريب الطلاب | 1 مدرسة فنية على مهارات ريادة الأعمال". r- مقترح بروتوكول تعاون مع شركة "أماديوس مصر" المسئولة عن تقديم خدمات حجز تذاكر الطيران لتدريب طلاب تخصص قسم الخدمات السياحية على برامج حجز تذاكر الطيران. ع- البدء فى إنشاء المدرسة الثانوية الفنية النووية بمنطقة الضبعة نظام الخمس سنوات بالتعاون مع وزارة الكهرباء والطاقة لتخريج فنيين بمجال صيانة محطات الطاقة النووية. 0- تقديم عشرات من المنح التدريبية لطلاب التعليم الفنى في تخصصات الكهرباء والالكترونات والميكاتروينكس لتدريبه في ألمانيا لمده ثلاث سنوات كفنيين "منح من

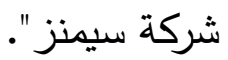




\section{واقع ازمة القيم فى التعليم الفنى قبل الجامعى الطلاب" ـــ م/ محمد احمد محمد عبد المقصود}

التوصيات

إن خريج التعليم الفنى لن يكون مهيأ لأداء حرفة معينة بالمهارة المطلوبة فور تخرجه

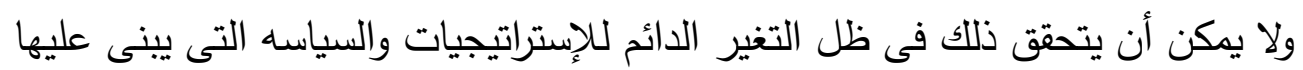
أى تطوير ، لذلك فإن هذه الدراسة لن توصى بإستراتيجيات جديدة ولكن يمكن التوصيه بالتالى حتى يتم بمقتضاها وضع سياسات تعليميه صادقه. - تغيير قانون التعليم وتحديد تعريف الخريج وفيما يخص التعليم الفنى فإنه يوصى بإقتصاره على نظام الثلاث سنوات فقط. - إتاحة الفرصه لخريج التعليم الفنى للألتحاق بالتعليم العالى "مسار الكليات التكنولوجية" بعد وضع الشروط والقواعد المنظمه لذلك. - وضع سياسه للتعليم الفنى ثابتة لعشر سنوات وهذه السياسات ينبغى أن يضعها لجنه مشكله من جميع الأطراف ذات المصلحه فى التعليم الفنى مبنية على معلومات دقيقة

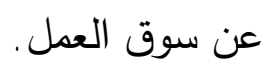

- أن تكون وزارة التعليم الفنى والتدريب جهة تتفيذيه فقط وليست جهة وضع سياسات تعليميه تتغير بتغير الوزير أو المسئولين عن التعليم الفنى. - تحديد جهة واحدة مسؤله مسؤليه تامه ومحاسبتها على سلامة ودقة قواعد البيانات وأهمها بيانات سوق العمل. - تتفيذ برنامج معلومات احتياجات سوق العمل بكافة قطاعات العمل الحكومي وقطاع الأعمال والقطاع الخاص والمشروعات القومية، ويتم معالجة البيانات بمركز معلومات برات مجلس دوريا. - استحداث برامج ثقافية تعمل على التتمية العقلية عند الطالب وتتمية مهارات التفكير والابتكار، والقدرة على المثابرة، والاصرار والانجاز وتثمين قيمة العمل وتفادى الهدر والاستهلاك. 


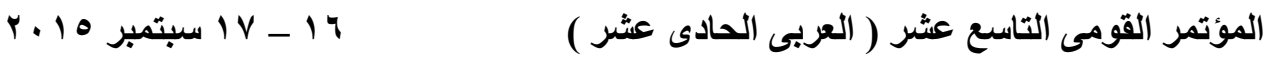
- مراعاة ان تتضمن كل المناهج إضافة الى سلوك المعلمين والإداريين - مايدعم القيم الأخلاقية بصفة عامة والسلوكيات السوية.

- دعم تدريس اللغات الأجنبية خاصة لغات الدول الجاذبة للعمالة الفنية مثل اللغة الايطالية، واللغات السائدة فى دول افريقية مثل نيجيريا وجنوب السودان وغيرها. - إعداد اختبارات ومقاييس قدرات وميول الطلاب المتقدمين للتعليم الفنى وتوظيفها بطرق إرشادية - فى قبول الطلاب بتخصصات التعليم الفنى. - إجراء دراسات وبحوث على طلاب وخريجي التعليم الفنى للتعرف على توجهاتهم وتطلعاتهم والصعوبات العلمية والنفسية التى قد يعانونها، وأرائهم فى تطوير التعليم الفني 


\section{واقع ازمة القيم فى التعليم الفنى قبل الجامعى الطلاب" ـــ م/ محمد احمد محمد عبد المقصود}

\section{المراجع العلمية}

- موقع وزارة التعليم الفنى والتدريب، خطة تطوير التعليم الفنى، 0 ـ ـ ب.

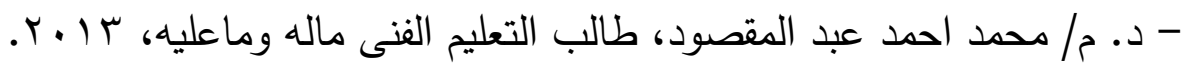
- المجلس القومى للتعليم، ملاءمة سياسات التعليم الفنى للوضع الإقتصادى بمصر ، $. Y . I T$

- المجلس القومى للتعليم، نحو استراتيجية قومية للتعليم الفنى، • 1 • r.

- د. مـ/ محمد صبري الثافعي، واقع وآفاق التعليم الفني والتدريب المهنى، ه ـ. . . - د.عبد اللطيف الهنيدى، سوق العمل فى مصر والعوامل المؤثرة فيه، 199 1. - د. محمد السيد حسونة، تطوير التعليم الفنى بمصر فى ضوء خبرات الدول المتقدمة، 1999.

- المجلس القومى للتعليم والبحث العلمى، دور التعليم الفنى فى سوق العمل،909 190 - د.عزة سليمان، العلاقات الترابطية بين البطالة ومستوى مخرجات التعليم الفنى، .1995

- موسوعة المجالس القومية المتخصصة، المجلد السادس، الدورة الخامسة عشرة، $.191 \mathrm{~V}$ 